\title{
Physical Properties and Behaviour of Highly Bi-Substituted Magneto-Optic Garnets for Applications in Integrated Optics and Photonics
}

\author{
Mohammad Nur-E-Alam, ${ }^{1}$ Mikhail Vasiliev, ${ }^{1}$ Kamal Alameh, ${ }^{1,2}$ and Viacheslav Kotov ${ }^{3}$ \\ ${ }^{1}$ Electron Science Research Institute, Edith Cowan University, Joondalup, WA 6027, Australia \\ ${ }^{2}$ Department of Nanobio Materials and Electronics, GIST, Gwangju, Republic of Korea \\ ${ }^{3}$ Institute of Radio Engineering and Electronics, Russian Academy of Sciences, 11 Mohovaya St., Moscow 125009, Russia
}

Correspondence should be addressed to Mohammad Nur-E-Alam, m.nur-e-alam@ecu.edu.au and

Mikhail Vasiliev, m.vasiliev@ecu.edu.au

Received 31 March 2011; Accepted 10 June 2011

Academic Editor: Steve Blair

Copyright (C 2011 Mohammad Nur-E-Alam et al. This is an open access article distributed under the Creative Commons Attribution License, which permits unrestricted use, distribution, and reproduction in any medium, provided the original work is properly cited.

\begin{abstract}
Rare-earth and Bi-substituted iron garnet thin film materials exhibit strong potential for application in various fields of science and frontier optical technologies. Bi-substituted iron garnets possess extraordinary optical and MO properties and are still considered as the best MO functional materials for various emerging integrated optics and photonics applications. However, these MO garnet materials are rarely seen in practical photonics use due to their high optical losses in the visible spectral region. In this paper, we report on the physical properties and magneto-optic behaviour of high-performance RF sputtered highly bismuth-substituted iron garnet and garnet-oxide nanocomposite films of generic composition type $(\mathrm{Bi}, \mathrm{Dy} / \mathrm{Lu})_{3}(\mathrm{Fe}, \mathrm{Ga} / \mathrm{Al})_{5} \mathrm{O}_{12}$. Our newly synthesized garnet materials form high-quality nanocrystalline thin film layers which demonstrate excellent optical and MO properties suitable for a wide range of applications in integrated optics and photonics.
\end{abstract}

\section{Introduction}

It is now more than 40 years since the giant magneto-optical effects in bismuth-substituted iron garnets (Bi:IG) were reported first in 1969 and used extensively for fabricating various magnetic recording media. But the synthesis efforts aimed at controlling the properties of Bi:IG compounds containing various metal dopants have started back in 1960s, and different methods were used, including Pulsed Laser Deposition (PLD), Liquid Phase Epitaxy (LPE), Ion Beam Sputtering (IBS), Reactive Ion Beam Sputtering (RIBS), Sol-gel process, and RF magnetron sputtering [1-9]. Bi:IGs are still considered to be the best magneto-optic (MO) material type among all known semitransparent materials and are therefore of interest for various optical, $\mathrm{MO}$, and other applications. The extraordinary MO properties of highly Bisubstituted iron garnet materials allow the modulation of the polarisation state and intensity of polarized light by means of applying external magnetic fields on a nanosecond time scale. Highly bismuth-substituted iron garnets are becoming more and more attractive nowadays for various application fields ranging from magnetic data recovery to quantum optical information processing [10-19]. Extensive studies have been conducted by multiple groups working world-wide to synthesize new garnet materials with properties suitable for various emerging technologies and having a high $\mathrm{Bi}$ content and also other metal-atom dopants like $\mathrm{Ga}$ or $\mathrm{Al}$ within the garnet structure. The physical properties (optical, magnetic, and $\mathrm{MO}$ ) of all garnet materials depend significantly not only on the Bi content and the substitution of other extra atoms and dopants within the sublattices of the garnet structure, but also on the multiple process parameters relevant to the synthesis of Bi:IGs [3]. The synthesis of high-quality Bi:IG thin film materials is usually a very complex and multistep process sequence which also requires complex multiparameter process optimizations applied at both the deposition 
and annealing stages. RF magnetron sputtering using lowpressure (1-5 mTorr) argon (Ar) plasma is one of the most flexible approaches to deposit MO garnet materials. The ability to vary the substrate temperature during the deposition and also the possibility of growing the films on relatively cold substrates are very important for the integration of Bi:IG films into optical devices. We prepare highly Bi-substituted dysprosium (or lutetium) iron garnet thin films using RF sputtering followed by the conventional (postdeposition) oven annealing in air atmosphere. Our MO garnet thin film materials are highly competitive (in terms of MO figure of merit) with all other garnet materials synthesized to date by using various modern microfabrication technologies.

In this paper, we report on the physical properties and behaviour (especially the magnetic switching behaviour) of several RF-sputtered high-performance, highly bismuthsubstituted ferrimagnetic garnet materials which are suitable for integration into various photonic devices and for many magneto-optic applications.

\section{Experimental}

2.1. RF Sputtering Processes and Thin Film Growth. Highly bismuth-substituted garnet films and also various cosputtered nanocomposite garnet-bismuth oxide thin films were fabricated by using RF magnetron sputtering system (Korea Vacuum Technology Ltd KVS-T 4065). The garnet and composite garnet-oxide thin films of different thicknesses (up to $1500 \mathrm{~nm}$ ) were prepared in a high-vacuum chamber using low-pressure argon (Ar) plasma at different substrate temperatures ranging between $250-680^{\circ} \mathrm{C}$ during the deposition. We prepared several batches of garnet thin films and also garnet-bismuth oxide composite films having different volumetric contents of $\mathrm{Bi}_{2} \mathrm{O}_{3}$ added by cosputtering from a separate target. The nominal stoichiometries of the sputtering targets $\mathrm{Bi}_{m} \mathrm{Dy}_{3-m} \mathrm{Fe}_{5-n} \mathrm{Ga}_{n} \mathrm{O}_{12}$ (where $m=2$ and $n=1$ and 0.7) and $\mathrm{Bi}_{a} \mathrm{Lu}_{3-a} \mathrm{Fe}_{5-b} \mathrm{Al}_{b} \mathrm{O}_{12}$ (where $a=1.2$ and $b=1.4)$ based on high-purity $(99.99 \%)$ oxide material mixes were selected to experiment with different levels of magnetostriction-induced uniaxial magnetic anisotropy. A separate $\mathrm{Bi}_{2} \mathrm{O}_{3}$ target was used as an external source of $\mathrm{Bi}$ oxide (and also $\mathrm{Bi}$ ) content for incorporation into the nanocomposite materials during cosputtering processes. A schematic diagram of our cosputtering geometry is shown in Figure 1 (up to two guns were used concurrently in our experiments). The target materials (garnet and oxide) of $3^{\prime \prime}$ diameter were placed at three RF guns of the down-sputtering system having about $18 \mathrm{~cm}$ of sourceto-substrate separation. All the guns with independently activated shutters are placed at the corners of the equilateral triangle and tilted towards the substrates. The substrates' stage rotation was adjusted to be near 40-50 rpm during the deposition processes to provide a good deposition thickness/composition uniformity of sputtered films on all substrates. The film thicknesses were always measured in two ways; thicknesses were monitored during the deposition and also remeasured after deposition using the spectrally bestfitted transmission spectra and also their measured refractive index and absorption spectra.
2.2. Oven Annealing Heat Treatment. The as-deposited films (amorphous-phase layers) were placed into a conventional box-furnace-type oven annealing system to anneal them in air atmosphere using the appropriate composition-dependent optimized isothermal crystallization regimes. The annealing processes were run to crystallize the sputtered thin films inside the oven with temperature ramp rates (up and down) in between $3-5^{\circ} \mathrm{C} / \mathrm{min}$, for a number of different annealing durations. We used low rates of temperature ramping during the annealing processes for our garnet-oxide composite materials to avoid the film surface degradation and microcrack formation in samples. We found that the optimization of annealing regimes (both temperature and annealing process durations were optimized) for our highly Bi-substituted garnet materials was strongly dependent on the composition of films. Figure 2 shows a photograph of (150 W $\mathrm{Bi}_{2} \mathrm{Dy}_{1} \mathrm{Fe}_{4.3} \mathrm{Ga}_{0.7} \mathrm{O}_{12}+30 \mathrm{~W} \mathrm{Bi}_{2} \mathrm{O}_{3}$, or having 37 vol. \% of excess $\mathrm{Bi}_{2} \mathrm{O}_{3}$ ) composite films on Corning 1737 glass (larger sample) and on a GGG (smaller sample) substrate having hazy and optically damaged (scatterer-type) surfaces due to over-annealing. These films were annealed in air atmosphere for only 30 minutes at $520^{\circ} \mathrm{C}$, with a temperature ramp (up/down) rate of $5^{\circ} \mathrm{C} / \mathrm{min}$. However, this amount of thermal exposure was already excessive, due to the rather high bismuth content of the deposited layers. It is evident that either the annealing temperature or the annealing duration or both were not optimized to form optically flat nanocrystalline layers from the amorphous phase of these garnet-oxide composites. So it is one of the important factors of garnet thin films synthesis to find an optimized annealing regimes as the optical and MO properties are vitally related to the optimization of the annealing regimes. Even though these films were optically spoiled, they still did demonstrate some useful MO properties in terms of Faraday rotation per unit film thickness as reported in a previous publication [10].

2.3. Thin-Film Materials Characterization. The structural, optical, magnetic, and MO properties of high-quality annealed garnet thin films were subjected to characterization using a number of characterization techniques. The crystal structure and impurity phases of garnet and garnet-bismuth oxide thin films of type $(\mathrm{BiDy})_{3}(\mathrm{Fe}, \mathrm{Ga})_{5} \mathrm{O}_{12}$ have been analyzed using X-ray diffractometry (XRD) data generated by Panalytical XPert Pro X-ray diffractometer configured for near-grazing-incidence powder diffraction measurements using the $\mathrm{CuK}_{\alpha 1}(\lambda=0.15406 \mathrm{~nm})$ radiation. The optical properties of garnet films were investigated by variableangle spectroscopic ellipsometry and also by deriving the absorption coefficient spectra, while the measurements of Faraday rotation hysteresis loops revealed the most important magnetic and MO properties of the garnet films. The specific Faraday rotation measurements were performed almost across the entire visible spectral region by using several laser light sources, a Thorlabs PAX polarimeter and an electromagnet. A transmission-mode polarizing microscope (Leitz Orthoplan) was used to observe the magnetic domain patterns of garnet films. 


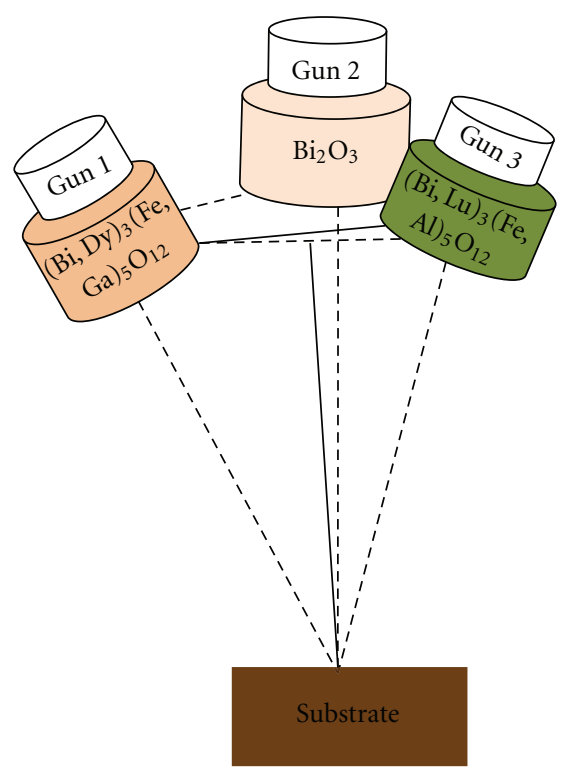

(a)

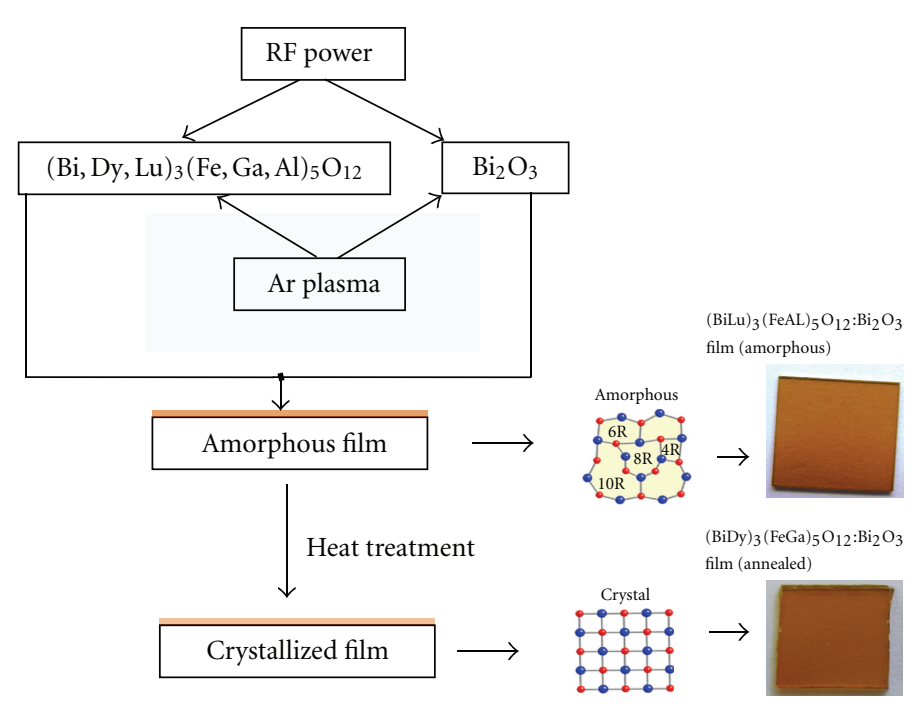

(b)

Figure 1: (a) Schematic diagram of the cosputtering system geometry, (b) flow chart of garnet-bismuth oxide cosputtered thin films processing.

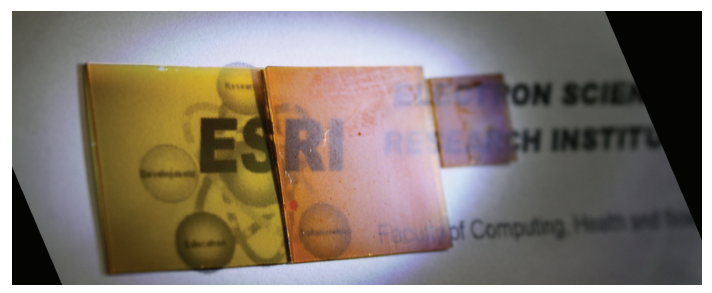

FIGURE 2: Photographs of a correctly annealed garnet-oxide composite thin film and two over-annealed films of composition type $\mathrm{Bi}_{2} \mathrm{Dy}_{1} \mathrm{Fe}_{4.3} \mathrm{Ga}_{0.7} \mathrm{O}_{12}: \mathrm{Bi}_{2} \mathrm{O}_{3}$ sputtered onto Corning 1737 (larger samples) and GGG (smaller sample) substrates. The transparent film (on the left) has a smaller thickness and high surface quality. The two over-annealed films were oven treated at $520^{\circ} \mathrm{C}$ for $30 \mathrm{~min}$.

\section{Results and Discussion}

The correctly annealed highly Bi-substituted magneto-optic doped-iron-garnet thin films demonstrated excellent optical properties across the visible and near-infrared spectral range. We observed very similar behaviours of the optical absorption spectra in both types of our sputtered garnet films (dysprosium iron garnets and lutetium iron garnets). It is important to note that lower absorption coefficients were always observed (as was expected) in the cosputtered garnetbismuth oxide composite thin films compared to the absorption of typical (stoichiometrically deposited) garnet layers. Figure 3 shows the absorption coefficient spectra measured in typical $(\mathrm{Bi}, \mathrm{Dy}, \mathrm{Lu})_{3}(\mathrm{Fe}, \mathrm{Ga}, \mathrm{Al})_{5} \mathrm{O}_{12}$ garnet layers and also those measured in the best-performing cosputtered garnetoxide $(\mathrm{Bi}, \mathrm{Dy}, \mathrm{Lu})_{3}(\mathrm{Fe}, \mathrm{Ga}, \mathrm{Al})_{5} \mathrm{O}_{12}: \mathrm{Bi}_{2} \mathrm{O}_{3}$ composite layers sputtered onto GGG (111) substrates. Similar trends in the absorption coefficient spectra were also observed in the films sputtered onto the glass (Corning 1737) substrates.
We have previously not only reported on the optical and magneto-optical properties of the sputtered $(\mathrm{Bi}, \mathrm{Dy})_{3}(\mathrm{Fe}, \mathrm{Ga})_{5} \mathrm{O}_{12}$ material type and its nanocomposite derivatives of type $(\mathrm{Bi}, \mathrm{Dy})_{3}(\mathrm{Fe}, \mathrm{Ga})_{5} \mathrm{O}_{12}: \mathrm{Bi}_{2} \mathrm{O}_{3}$ but also documented their annealing behaviour and the effects of thermal exposure on the resulting optical and MO properties $[10,16]$. We have also reported on the synthesis of RF-sputtered garnet materials of composition type $\mathrm{Bi}_{1.8} \mathrm{Lu}_{1.2} \mathrm{Fe}_{3.6} \mathrm{Al}_{1.4} \mathrm{O}_{12}$ for the first time, and we believe that no physical vapour deposition methods have so far been used previously to synthesize this material type with a high Bi-content (near two formula units) [17]. The codeposited nanocomposite derivatives of type $(\mathrm{Bi}, \mathrm{Lu})_{3}(\mathrm{Fe}, \mathrm{Al})_{5} \mathrm{O}_{12}: \mathrm{Bi}_{2} \mathrm{O}_{3}$ have been under investigation, and the detailed results will be reported elsewhere soon. The addition of excess $\mathrm{Bi}_{2} \mathrm{O}_{3}$ to the base garnet composition of type $\mathrm{Bi}_{1.8} \mathrm{Lu}_{1.2} \mathrm{Fe}_{3.6} \mathrm{Al}_{1.4} \mathrm{O}_{12}$ during cosputtering did not have much influence on the Faraday rotation of the garnet layers but significantly reduced the optical absorption. The garnet-oxide composite films of type $(\mathrm{Bi}, \mathrm{Lu})_{3}(\mathrm{Fe}, \mathrm{Al})_{5} \mathrm{O}_{12}: \mathrm{Bi}_{2} \mathrm{O}_{3}$ (4.5 vol.\% extra bismuth oxide) possessed extremely large $\mathrm{MO}$ figure of merit (more than $50^{\circ}$ at $635 \mathrm{~nm}$ ), which was more than three times higher than that of the typical garnet layer (Figure 4). Figure 4. shows the values of the specific Faraday rotation achieved and MO figures of merit measured using $532 \mathrm{~nm}$ and $635 \mathrm{~nm}$ light.

The X-ray diffraction patterns of $\mathrm{Bi}_{2} \mathrm{Dy}_{1} \mathrm{Fe}_{4} \mathrm{Ga}_{1} \mathrm{O}_{12}$ and $(\mathrm{BiDy})_{3}(\mathrm{FeGa})_{5} \mathrm{O}_{12}: \mathrm{Bi}_{2} \mathrm{O}_{3}$ layers synthesized on glass substrates are presented in Figure 5. The data reveals the nanocrystalline microstructure of the annealed garnet materials and the body-centered cubic lattice structure type, as well as only one identifiable impurity phase $\left(\mathrm{Fe}_{3} \mathrm{O}_{4}\right)$ being present. The addition of extra $\mathrm{Bi}_{2} \mathrm{O}_{3}$ always reduced the relative intensities of the iron-oxide diffraction peaks, as witnessed by the diffraction datasets of the films synthesized by cosputtering. This indicates the presence of less iron oxide outside 


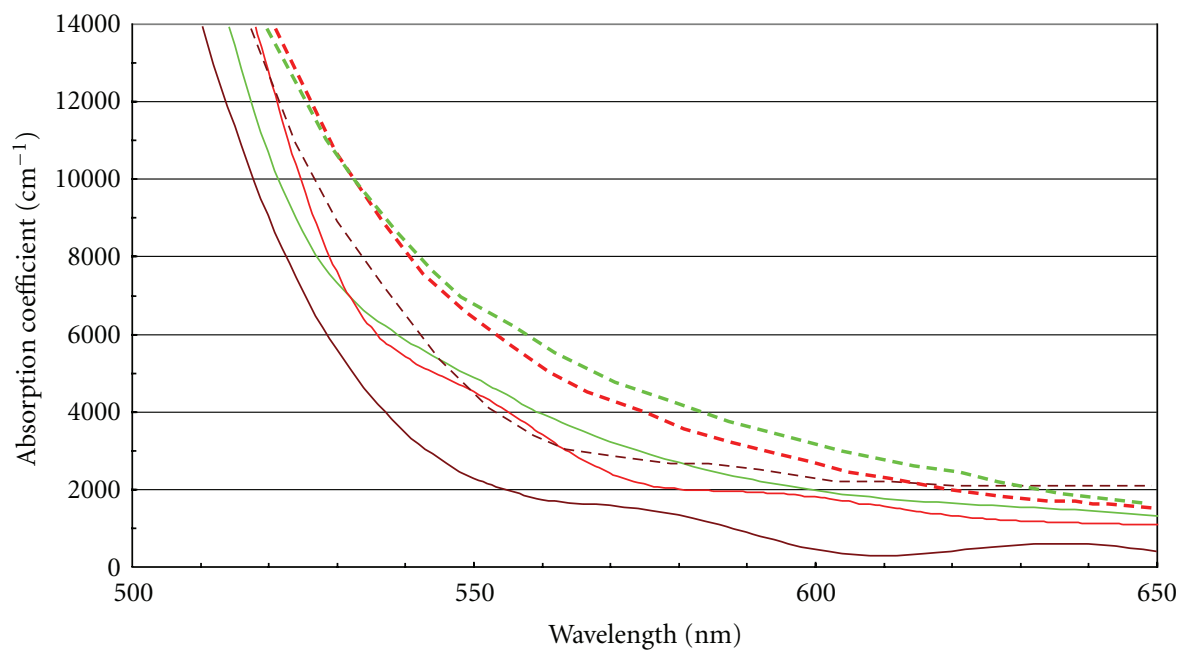

- - - Typical $\mathrm{Bi}_{2} \mathrm{Dy}_{1} \mathrm{Fe}_{4.3} \mathrm{Ga}_{0.7} \mathrm{O}_{12}$ garnet film on GGG, annealed for $1 \mathrm{hr}$ at $680^{\circ} \mathrm{C}$

- - Typical $\mathrm{Bi}_{2} \mathrm{Dy}_{1} \mathrm{Fe}_{4} \mathrm{Ga}_{1} \mathrm{O}_{12}$ garnet film on GGG, annealed for $1 \mathrm{hr}$ at $700^{\circ} \mathrm{C}$

- - - Typical $\mathrm{Bi}_{1.8} \mathrm{Lu}_{1.2} \mathrm{Fe}_{3.6} \mathrm{Al}_{1.4} \mathrm{O}_{12}$ garnet film on GGG, annealed for $1 \mathrm{hr}$ at $650^{\circ} \mathrm{C}$

- $\mathrm{Bi}_{2} \mathrm{Dy}_{1} \mathrm{Fe}_{4.3} \mathrm{Ga}_{0.7} \mathrm{O}_{12}: \mathrm{Bi}_{2} \mathrm{O}_{3}$ (est. 23.6 vol\%) composite on GGG, annealed for $1 \mathrm{hr}$ at $560^{\circ} \mathrm{C}$

- $\mathrm{Bi}_{2} \mathrm{Dy}_{1} \mathrm{Fe}_{4} \mathrm{Ga}_{1} \mathrm{O}_{12}: \mathrm{Bi}_{2} \mathrm{O}_{3}$ (est. 23.3 vol\%) composite on GGG, annealed for $2 \mathrm{hrs}$ at $580^{\circ} \mathrm{C}$

- $\mathrm{Bi}_{1.8} \mathrm{Lu}_{1.2} \mathrm{Fe}_{3.6} \mathrm{Al}_{1.4} \mathrm{O}_{12}: \mathrm{Bi}_{2} \mathrm{O}_{3}$ (est. 4.5 vol\%) composite on GGG, annealed for 10 hrs at $610^{\circ} \mathrm{C}$

FIGURE 3: Derived absorption coefficient spectra of the best-performing garnet layer types and these of the garnet-oxide composite (having different vol.\% content of excess $\mathrm{Bi}_{2} \mathrm{O}_{3}$ ) films deposited onto GGG (111) substrates.

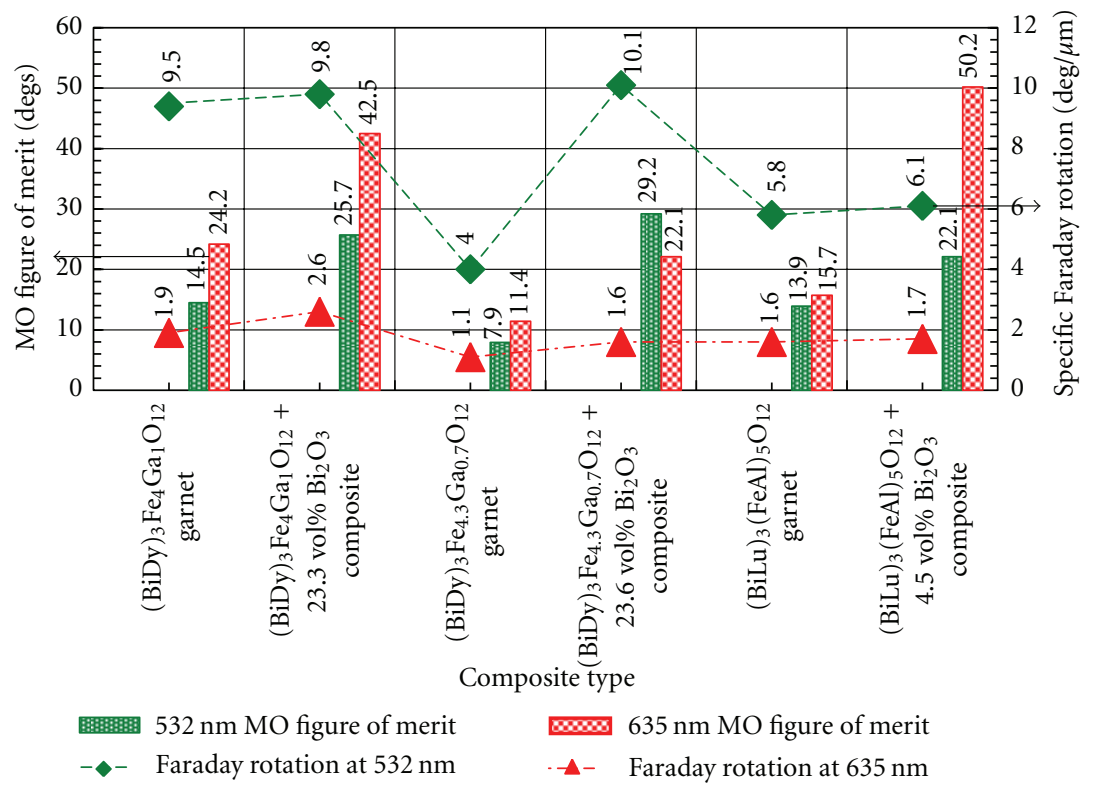

FIGURE 4: Summary of the measured specific Faraday rotation data (dashed lines) and MO figures of merit (bar diagrams) of different garnet and garnet-oxide composite layer types; the highest values (of the specific Faraday rotation and MO figure of merit) achieved in our experiments so far are indicated.

the garnet nanocrystallites. No diffraction peaks characteristic of $\mathrm{Bi}_{2} \mathrm{O}_{3}$ have been observed since the bismuth oxide remained in its amorphous phase even after the annealing treatments.

Figure 6 shows the hysteresis loops of specific Faraday rotation at $532 \mathrm{~nm}$ measured in several best-performing garnet-bismuth oxide nanocomposite films, which had different coercive force, saturation field, and switching field values.
The effects of extra bismuth oxide incorporation on the MO properties were investigated, and also the influence of the volumetric content of extra bismuth oxide was observed (Figure 6(a)). Our experimental results revealed that by controlling the volumetric content of extra $\mathrm{Bi}_{2} \mathrm{O}_{3}$ it was possible to control (to some degree) the magnetic switching behaviour and the coercive force value of garnetoxide nanocomposite media. This type of control over the 


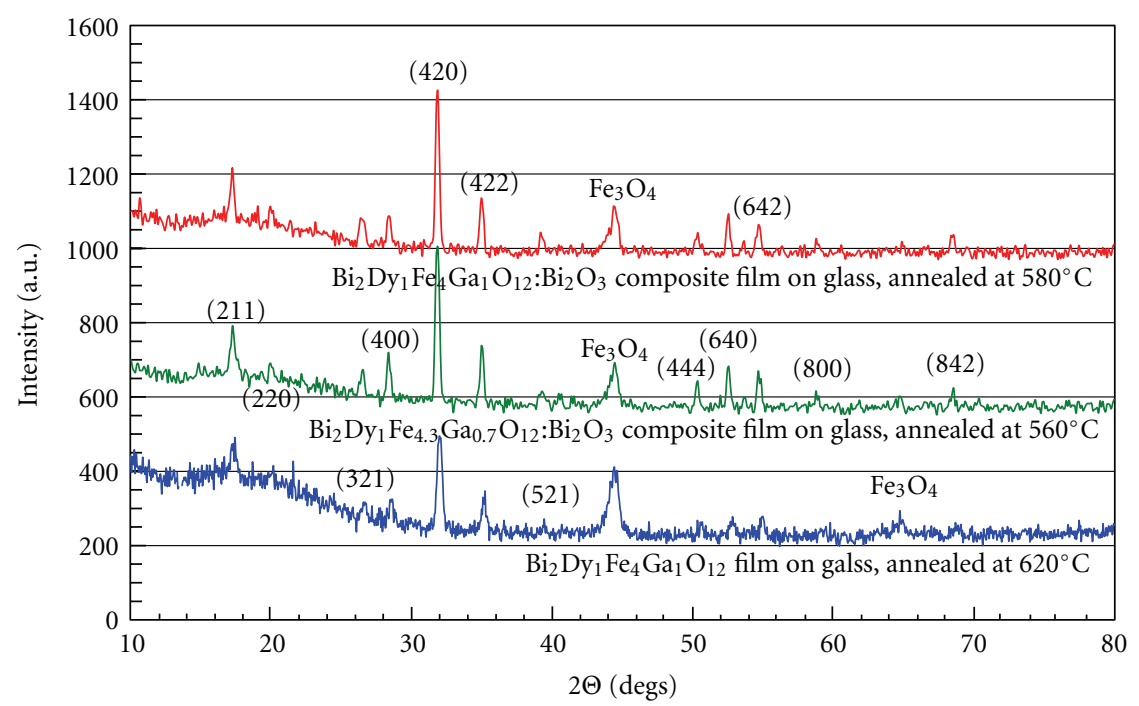

FIGURE 5: X-ray diffraction patterns of several sputtered Bi-substituted thin-film garnet materials deposited onto glass substrates.

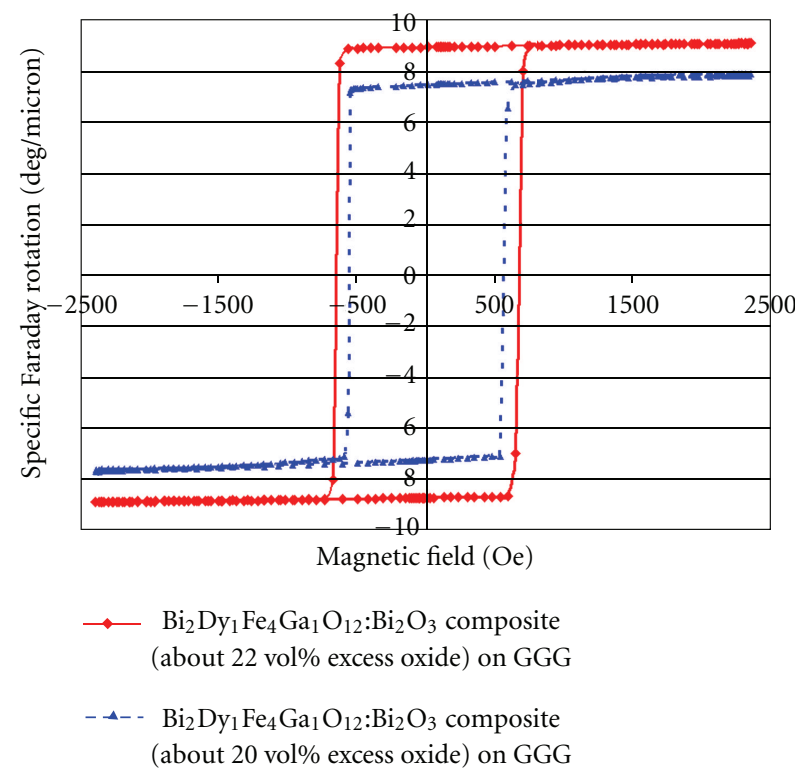

(a)

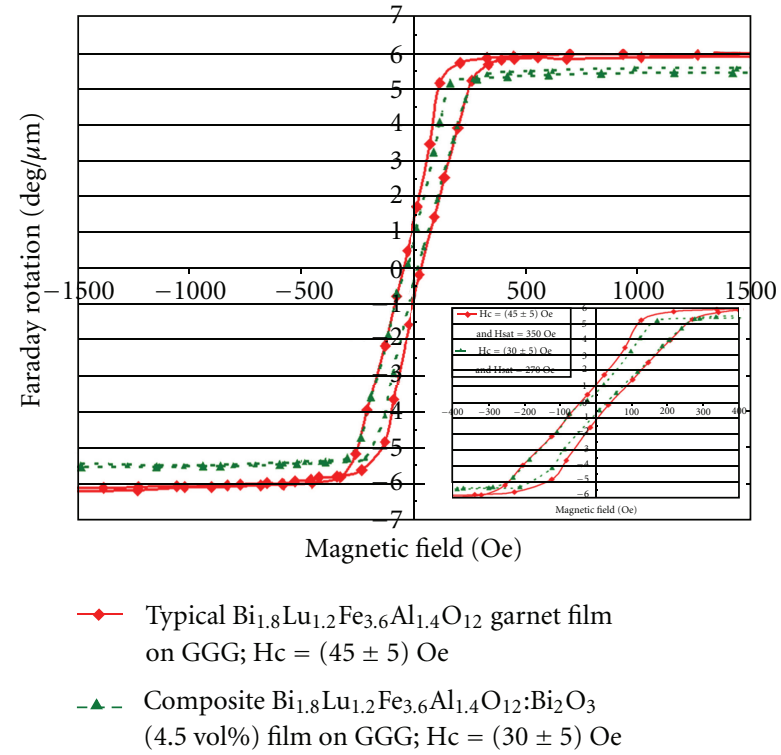

(b)

FIGURE 6: Hysteresis loops of specific Faraday rotation measured using a $532 \mathrm{~nm}$ laser source in several highly Bi-substituted iron garnetbismuth oxide nanocomposite films of types (a) (BiDy) $)_{3}(\mathrm{FeGa})_{5} \mathrm{O}_{12}: \mathrm{Bi}_{2} \mathrm{O}_{3}$ and (b) ( $\left.\mathrm{BiLu}\right)_{3}(\mathrm{FeAl})_{5} \mathrm{O}_{12}: \mathrm{Bi}_{2} \mathrm{O}_{3}$, deposited onto GGG (111) substrates.

magnetic properties can lead towards achieving tunability in magneto-photonic crystals, which is very essential for different types of applications including the optical isolators and optical polarization controllers. The experimental setup for characterization of magneto-optic switching response as well as magnetization dynamics has been described in [20]. Nanosecond-range switching response times of below $20 \mathrm{~ns}$ were measured previously in $1 \sim 2 \mu \mathrm{m}$ thick highly Bi-substituted iron garnet films of composition type $(\mathrm{Bi}, \mathrm{Dy})_{3}(\mathrm{Fe}, \mathrm{Ga})_{5} \mathrm{O}_{12}$. Note that the high-speed switching time constant of $2.4 \mathrm{~ns}$ has also been measured in $\mathrm{Bi}_{3} \mathrm{Fe}_{4} \mathrm{Ga}_{1} \mathrm{O}_{12}$ garnet films of $1 \mathrm{~mm}$ aperture size at $532 \mathrm{~nm}$
[13]. On the other hand, rather low coercive force values were measured in the second type of thin film materials studied (bismuth-substituted lutetium iron garnets doped with aluminium) sputtered onto GGG (111) substrates. The measured coercive force for the films on GGG substrates was about $45 \mathrm{Oe}$, whereas the addition of extra bismuth oxide into the films reduced the coercivity of the films as indicated in the inset (Figure 6(b)). We measured a high Faraday-effect magnetic field sensitivity within the linear range of magnetizations of up to $42.8^{\circ} /(\mathrm{cm} \cdot \mathrm{Oe})$ at $635 \mathrm{~nm}$, which was higher than that obtained previously in epitaxial $(\mathrm{BiLu})_{3}(\mathrm{FeGa})_{5} \mathrm{O}_{12}$ films prepared by LPE [18]. 


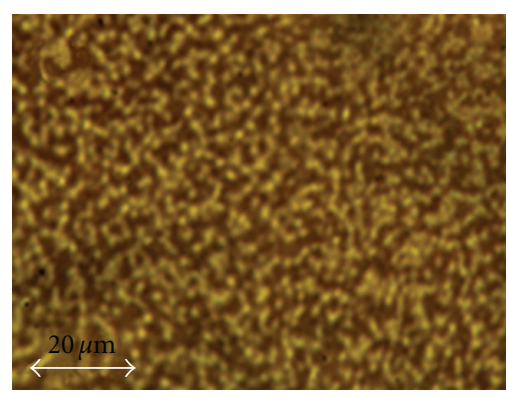

(a)

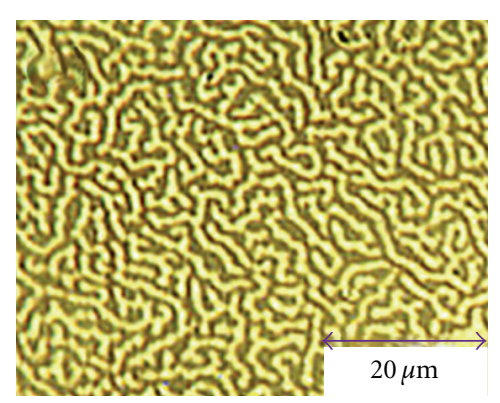

(b)

FIGURE 7: Magnetic domain patterns obtained in two different garnet-bismuth oxide composite thin films $(a) \mathrm{Bi}_{2} \mathrm{Dy}_{1} \mathrm{Fe}_{4} \mathrm{Ga}_{1} \mathrm{O}_{12}$ : $\mathrm{Bi}_{2} \mathrm{O}_{3}$, with an est. $23 \%$ of excess oxide, and (b) $\mathrm{Bi}_{1.8} \mathrm{Lu}_{1.2} \mathrm{Fe}_{3.6} \mathrm{Al}_{1.4} \mathrm{O}_{12}: \mathrm{Bi}_{2} \mathrm{O}_{3}$, with an est. $4.5 \%$ of excess bismuth oxide sputtered onto GGG (111) substrates.

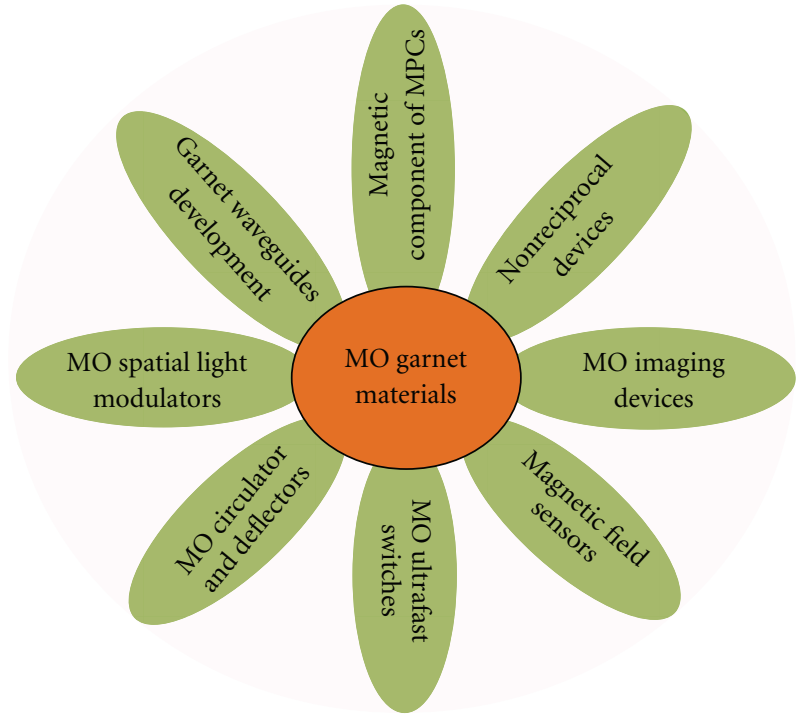

FIGURE 8: The existing and potential new application areas of MO garnet materials.

We also measured even lower coercive force values of less than $20 \mathrm{Oe}$ in thin films sputtered onto GGG at high substrate temperatures near $680^{\circ} \mathrm{C}$.

The magnetic domain structures observed in our two different types of garnet-bismuth oxide composite thin films in the absence of externally applied magnetic fields are shown in Figure 7. The domain patterns were observed using a transmission-mode polarizing microscope.

The combination of physical properties of the highly Bi-substituted iron garnets of both types shows a great promise for the future development of different emerging types of integrated and reconfigurable nanophotonic devices. Garnet thin films of type $(\mathrm{BiDy})_{3}(\mathrm{FeGa})_{5} \mathrm{O}_{12}$ demonstrated simultaneously a record high MO quality, and strong uniaxial magnetic anisotropy will be attractive for visible-range and near-infrared applications, including the development of high-performance magnetic field visualizers and integrated optical polarization controllers. The garnet films of type $(\mathrm{BiLu})_{3}(\mathrm{FeAl})_{5} \mathrm{O}_{12}$ feature magnetically soft behaviour and possess a significant in-plane magnetization component which will be especially suitable for the development of garnet waveguides, nonreciprocal integrated optics components as well as the magnetic field imaging and sensing devices.

\section{Applications of RF-Sputtered Garnet Materials}

Modern civilization demands superior technologies and high-speed communication systems for achieving a better lifestyle. It is the challenge for modern science and technology to serve the requirements of society by providing all required technological facilities through new research, inventions, and reconfiguration of the existing devices and technologies. Materials science is one of the branches of science that can achieve rapid progress in research and applications for many new and existing technologies. A wide and growing range of applications require the design and development of new photonic materials (including MO garnet materials) which can enable control over the interaction of light with matter. MO garnet materials, especially the Bi-substituted iron garnet compounds are very suitable for various applications (Figure 8) including lightwave polarization controllers, MO flaw detection, high-density magnetic recording and MO data recovery, high-speed spatial and temporal light modulators, magnetic nanostructures for ultracold atoms trapping, and the development of magnetic photonic crystals (MPCs). The combination of the remarkable properties of magnetic garnet materials shows great promise for applications in next-generation integrated optics, nanophotonics, and also in reconfigurable photonics. The development of new garnet-type materials by synthesizing Bi-substituted iron garnets and their codeposited nanocomposite garnetoxide derivatives will not only allow the integration of garnet-based components into existing integrated-optics manufacturing processes, but will also help achieve cost efficiency by providing the functional materials which are technologically compatible with the presently used material combinations. That will have influence on numerous communities, because most of the innovative technologies using these advanced materials will be easy to implement and less 
costly.

\section{Conclusions}

We have synthesized a range of bismuth-substituted iron garnet thin-film materials having different bismuth substitution levels and metal dopants using the RF magnetron sputtering technique, which is one of the most common physical vapour deposition methods. We have characterized the nanocrystalline thin-film garnet materials crystallized using high-temperature oven processing and found the ways of achieving low optical absorption losses, relatively high specific Faraday rotation, and also some control over the magnetic switching behaviour. Our newly synthesized MO materials of two different composition types possess record high MO figures of merit in conjunction with other excellent physical properties which are attractive for use in various integrated-optics and photonics applications.

\section{Acknowledgments}

The authors would like to acknowledge the support of the Faculty of Computing, Health and Science, Edith Cowan University, Australia, and the Department of Nanobio Materials and Electronics, Gwangju Institute of Science and Technology, Republic of Korea. They would also like to pay special thanks to the Materials Characterization Lab, Korea Optical Technology Institute (KOPTI, Gwangju, South Korea) for performing the XRD data acquisition.

\section{References}

[1] C. F. Buhrer, "Faraday rotation and dichroism of bismuth calcium vanadium iron garnet," Journal of Applied Physics, vol. 40, no. 11, pp. 4500-4502, 1969.

[2] G. B. Scott and D. E. Lacklison, "Magnetooptic properties and applications of bismuth substituted iron garnets," IEEE Transactions on Magnetics, vol. 12, no. 4, pp. 292-311, 1976.

[3] A. K. Zvezdin and V. A. Kotov, Modern Magnetooptics and Magnetooptical Materials, Institute of Physics Publishing, Philadelphia, Pa, USA, 1997.

[4] S. H. Wee, H. S. Hong, Y. H. Kim, S. I. Yoo, and J. Kang, "Fabrication and characterization of Bi-substituted yttrium iron garnet films by pulsed laser deposition," Metals and Materials International, vol. 9, no. 5, pp. 507-511, 2003.

[5] T. Okuda, N. Koshizuka, K. Hayashi, T. Takahashi, H. Kotani, and H. Yamamoto, "Epitaxial growth of Bi-substituted yttrium iron garnet films by ion beam sputtering," Journal of the Magnetics Society of Japan, supplement 1, pp. 179-182, 2011, Proceedings of the International Symposium on MagnetoOptics, Advances in Magneto-Optics.

[6] T. Okuda, T. Katayama, H. Kobayashi, N. Kobayashi, K. Satoh, and H. Yamamoto, "Magnetic properties of $\mathrm{Bi}_{3} \mathrm{Fe}_{5} \mathrm{O}_{12}$ garnet," Journal of Applied Physics, vol. 67, no. 9, pp. 4944-4946, 1990.

[7] M. Duan, A. M. Grishin, K. V. Rao, and T. Suzuki, "Laser deposited bismuth doped iron garnet films with perpendicular anisotropy," IEEE Transactions on Magnetics, vol. 31, no. 6, pp. 3245-3246, 1995.
[8] Y. Zhang, X. Wang, H. Xia et al., "Characterization of Bisubstituted dysprosium iron garnet films prepared Sol-gel process," Journal of Materials Sciences and Technology, vol. 20, no. 1, pp. 66-68, 2004.

[9] M. Vasiliev, M. Nur-E-Alam, V. A. Kotov et al., "RF magnetron sputtered $(\mathrm{BiDy})_{3}(\mathrm{FeGa})_{5} \mathrm{O}_{12}: \mathrm{Bi}_{2} \mathrm{O}_{3}$ composite garnet-oxide materials possessing record magneto-optic quality in the visible spectral region," Optics Express, vol. 17, no. 22, pp. 1951919535, 2009.

[10] M. Nur-E-Alam, M. Vasiliev, and K. Alameh, "Nano-structured magnetic photonic crystals for magneto-optic polarization controllers at the communication-band wavelengths," Optical and Quantum Electronics, vol. 41, no. 9, pp. 661-669, 2010.

[11] A. Abdelrahman, M. Vasiliev, K. Alameh, and P. Hannaford, "Asymmetrical two-dimensional magnetic lattices for ultracold atoms," Physical Review A, vol. 82, no. 1, Article ID 012320, 6 pages, 2010.

[12] I. L. Lyubchanskii, N. N. Dadoenkova, M. I. Lyubchanskii, E. A. Shapovalov, and T. Rasing, "Magnetic photonic crystals," Journal of Physics D, vol. 36, no. 18, pp. R277-R287, 2003.

[13] S. Kang, S. Yin, V. Adyam, Q. Li, and Y. Zhu, " $\mathrm{Bi}_{3} \mathrm{Fe}_{4} \mathrm{Ga}_{1} \mathrm{O}_{12}$ garnet properties and its application to ultrafast switching in the visible spectrum," IEEE Transactions on Magnetics, vol. 43, no. 9, pp. 3656-3660, 2007.

[14] T. Kim, S. Nasu, and M. Shima, "Growth and magnetic behavior of bismuth substituted yttrium iron garnet nanoparticles," Journal of Nanoparticle Research, vol. 9, no. 5, pp. 737-743, 2007.

[15] M. Vasiliev, M. Nur-E-Alam, K. Alameh et al., "Annealing behaviour and crystal structure of RF-sputtered Bi-substituted dysprosium iron-garnet films having excess co-sputtered Bioxide content," Journal of Physics D, vol. 44 , article 075002, no. 7, 2011.

[16] M. Nur-E-Alam, M. Vasiliev, K. Alameh, and V. Kotov, "High-quality RF-sputtered magneto-optic garnet films of $\mathrm{Bi}_{1.8} \mathrm{Lu}_{1.2} \mathrm{Fe}_{3.6} \mathrm{Al}_{1.4} \mathrm{O}_{12}$ with low coercivity for applications in integrated optics, imaging and sensing devices," in Proceedings of the International Conference on High-capacity Optical Networks and Enabling Technologies Conference, Cairo, Egypt, December 2010.

[17] N. Adachi, K. Obata, T. Okuda, T. Machi, and N. Koshizuka, "Synthesis of Bi-Lu-substituted iron garnet films for visualization of magnetic flux in high-Tc superconductors," Japanese Journal of Applied Physics, vol. 41, no. 10, pp. 5986-5990, 2002.

[18] M. Nur-E-Alam, M. Vasiliev, K. Alameh, and C. Valli, "Magneto-optical visualisation for high-resolution forensic data recovery using advanced thin film nano-materials," in Proceedings of the International Cyber Resilience Conference, Perth, WA, Australia, August 2010.

[19] M. Vasiliev, M. Nur-E-Alam, K. Alameh, and V. Kotov, "The properties of nanocomposite $(\mathrm{BiDy})_{3}(\mathrm{FeGa})_{5} \mathrm{O}_{12}: \mathrm{Bi}_{2} \mathrm{O}_{3}$ magneto-optic garnet films for applications in nanophotonics, ultrafast switching and integrated optoelectronics," in Proceedings of the International Conference on High-Capacity Optical Networks and Enabling Technologies Conference, Cairo, Egypt, December 2010.

[20] M. Vasiliev, V. I. Belotelov, K. E. Alameh, R. Jeffery, V. A. Kotov, and A. K. Zvezdin, "Tunable integrated-optics nanoscaled devices based on magnetic photonic crystals," in Proceedings of the ENS, Paris, France, December 2005. 

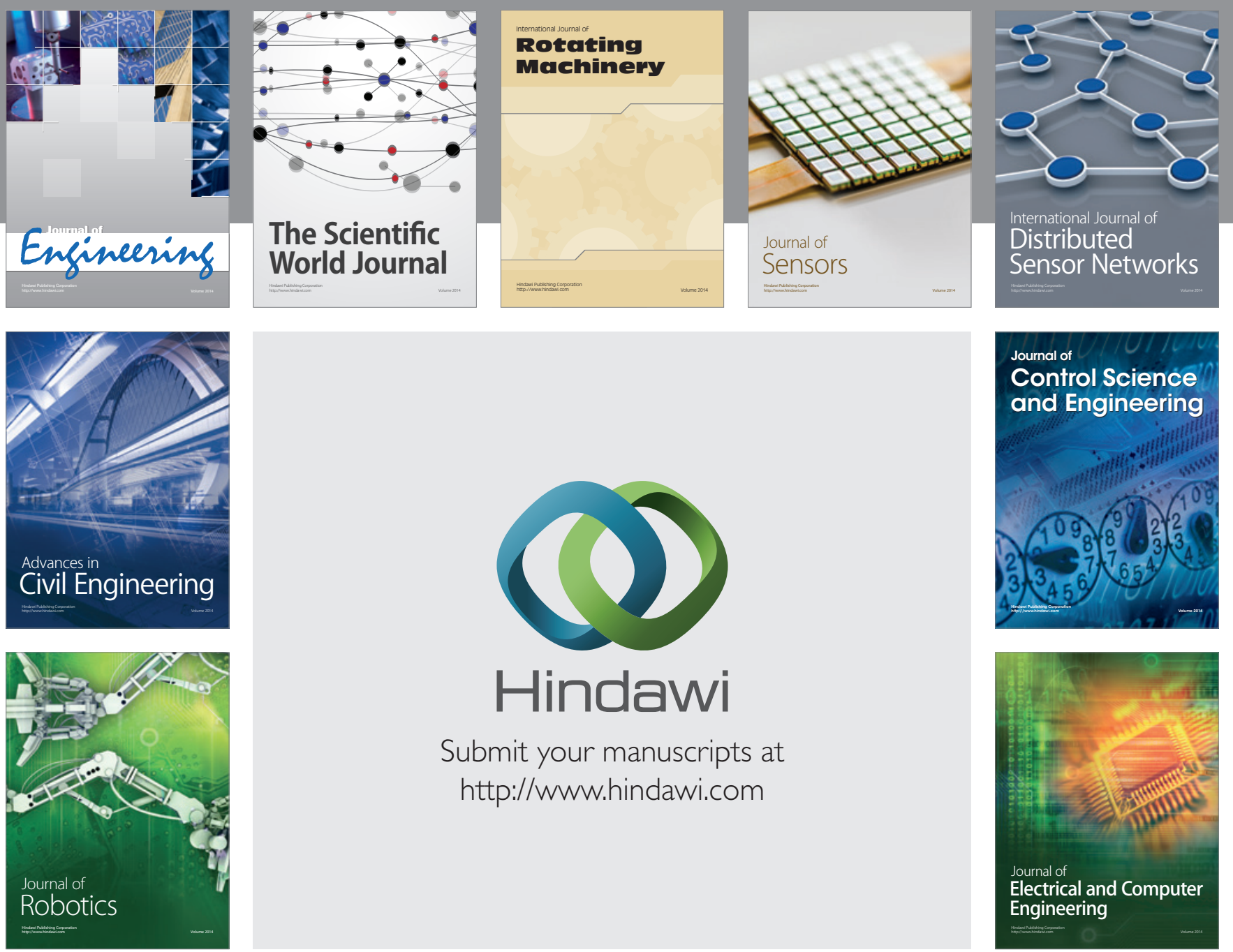

Submit your manuscripts at

http://www.hindawi.com
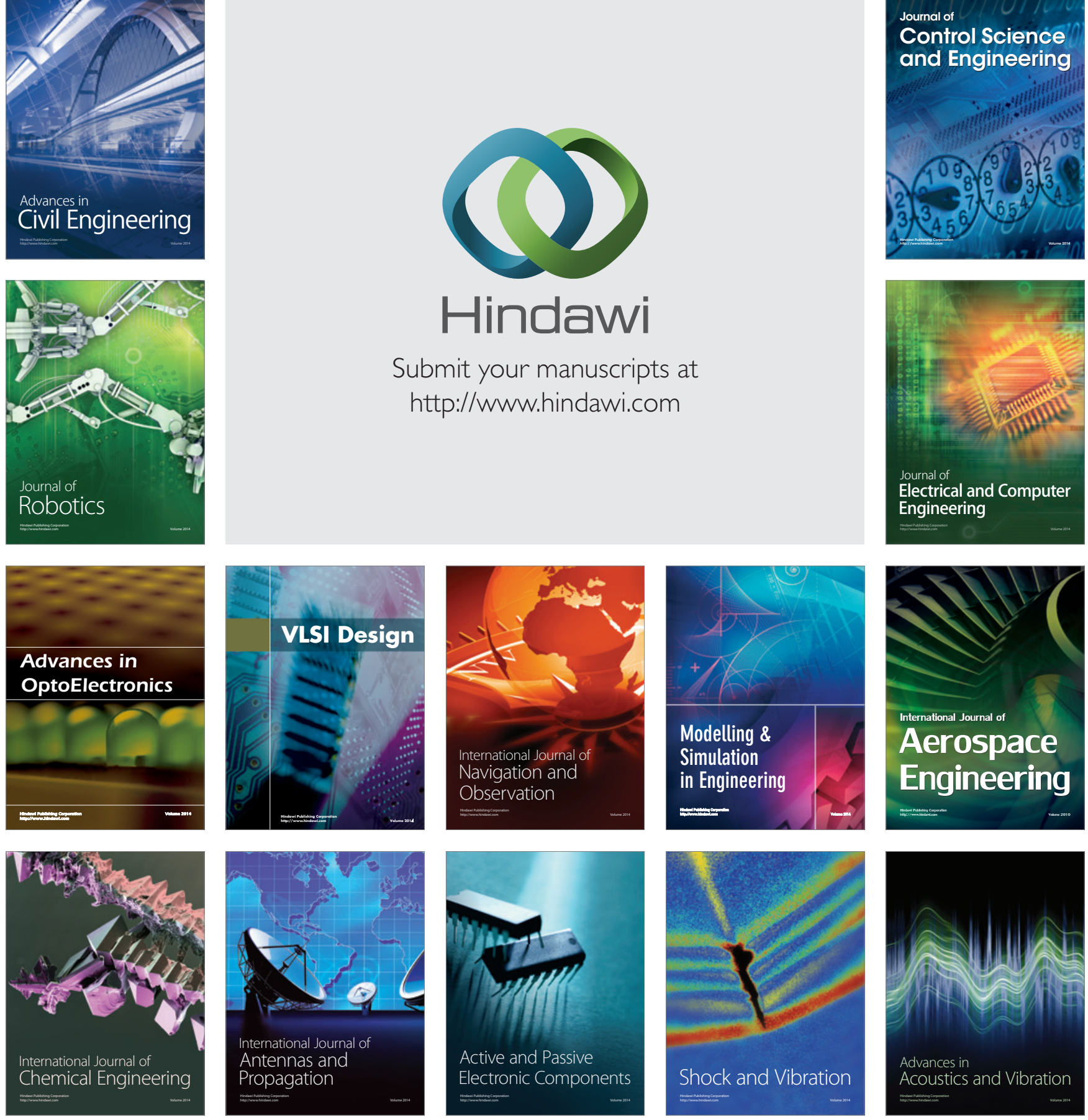